Check for updates

Cite this: RSC Adv., 2019, 9, 5786

\title{
Biomimetic composite scaffold from an in situ hydroxyapatite coating on cellulose nanocrystals
}

\author{
Chen Huang, ${ }^{\text {abc }}$ Samarthya Bhagia, (D) cf Naijia Hao, ${ }^{c}$ Xianzhi Meng, (D) ${ }^{c}$ Luna Liang, ${ }^{c}$ \\ Qiang Yong (D)*ab and Arthur J. Ragauskas (D)*cde
}

A novel nanocomposite scaffold was developed by homogeneous deposition of hydroxyapatite (HAP) on a cellulose nanocrystals (CNCs) matrix suspended in a simulated body fluid (SBF). By adjusting the pH of the SBF, the HAP content in the nanocomposite could be controlled between $15 \mathrm{wt} \%$ and $47 \mathrm{wt} \%$. Physical and chemical characteristics of the nanocomposites were analyzed by SEM, FTIR, XRD, SAED, and TEM, which confirmed the successful incorporation of HAP onto the CNCs. The nanocomposites were then freeze-casted into porous scaffolds by different solidification technologies (i.e., directional freezing (DF), plunging in liquid $\mathrm{N}_{2}(\mathrm{PL})$ or in a $-20{ }^{\circ} \mathrm{C}$ freezer (FZ)) followed by lyophilization. Compression testing of the HAP/CNCs foams indicated that DF caused significant improvement in mechanical properties due to the specific orientation and anisotropic porous structure compared to conventional freezing methods such as PL and FZ. Moreover, the scaffold with high HAP content exhibited improved mechanical and thermal properties, which holds potential for application in bone tissue engineering.

Received 19th November 2018 Accepted 5th February 2019

DOI: 10.1039/c8ra09523j

rsc.li/rsc-advances
HAP to enhance their osteoconductivity and hemocompatibility.$^{\mathbf{8 - 1 0}}$ However, these approaches have not yet fully addressed all the requirements needed for successful bone scaffolds due to their inherent drawbacks like poor mechanical properties and lack of flexibility, ${ }^{\mathbf{1 1 - 1 3}}$ and research is ongoing in several fields, including on the use of several alternative materials such as nanocellulose. ${ }^{\mathbf{1 4}}$

Cellulose nanocrystals (CNCs), a strong and promising natural material derived from native cellulose, have attracted tremendous interest due to their excellent physical and chemical properties and hold much potential for conversion into biobased materials that are rigid, biocompatible, nonimmunogenic and renewable. ${ }^{15}$ These rod-like crystalline cellulose structures are typically $5-20 \mathrm{~nm}$ in diameter and several hundred nanometers in length. ${ }^{16}$ It has been reported that the CNCs have an average Young's modulus around $130 \mathrm{GPa}$, even stronger than steel. ${ }^{17}$ In addition, CNCs are highly hydrophilic with a multitude of hydroxyl groups available, which can offer binding sites for bone cells and make it superior to other materials such as collagen and silk fibroin. ${ }^{18}$ Because of these excellent properties, CNCs have been successfully applied in many fields, such as drug delivery systems, tissue substitutes, hydrogels, conductive films, filtration membranes, and in composites as a reinforcement agent to enhance their physical properties. ${ }^{19,20}$ Although CNCs are not capable of being degraded in the human body, it is highly biocompatible which will not cause any inflammatory response after implanting. ${ }^{21}$ The use of CNCs associated with HAP as a template for developing bone substitute is a field of growing 
interest. Kumar et al. (2014) reported a polyvinyl alcohol/HAP/ CNCs composite, showing enhanced mechanical property as with the incorporation of CNCs. ${ }^{22}$ Through a sol-gel method, Herdocia-Lluberes et al. (2015) fabricated a CNCs/HAP pellet composite which could promote the proliferation of the osteoblast cells. ${ }^{23}$ Moreover, Saska et al. (2011) conducted in vivo test with a novel bacteria cellulose/HAP membrane, and results showed that the membrane could accelerate the new bone formation. ${ }^{24}$ These results suggest a promising perspective for using this composite in bone tissue engineering.

However, almost all the studies concerning CNCs/HAP composite were prepared by just blending HAP and CNCs, resulting in a heterogeneous mixture with relatively poor mechanical properties. During the preparation of nanocellulose by sulfuric acid hydrolysis, the surface of such CNCs was activated by the introduction of sulfonic groups. It was hypothesized that ionic groups could be induced to precipitate on CNCs by electrostatic interactions if such activated CNCs was put into a solution containing various ionic groups. Thus, a novel in situ HAP coating on individual CNCs fiber by immersing into a simulated body fluid (SBF) containing calcium ions and phosphate groups was developed herein this study. The content of HAP particles was controlled by adjusting the $\mathrm{pH}$ of the solution. Scanning electron microscopy (SEM), transmission electron microscopy (TEM), X-ray diffraction (XRD), selected area electron diffraction (SAED) and Fourier transform infrared spectroscopy (FTIR) were used to confirm the existence of such HAP coating. Moreover, the HAP coated CNCs nanocomposite was then freeze-casted into porous scaffolds by different freezing technologies, in which the directional freezing formed an orientated structure and was anticipated to improve the mechanical property.

\section{Experimental section}

\subsection{Materials}

CNCs purchased from the University of Maine were prepared by sulfuric acid hydrolysis of wood pulp, possessing a dimension of 5-20 nm in width and 150-200 $\mathrm{nm}$ in length. The obtained product was an aqueous slurry (12.1 wt\%) and the sulfur content of the CNCs was $0.95 \mathrm{wt} \%$. All the other chemicals of analytical grade were purchased from Fisher Scientific (Waltham, MA, USA) and used as received without further purification unless otherwise noted.

\subsection{Fabrication of CNCs/HAP composite}

A simplified SBF was prepared based on a previous report by Ishikawa et al. (2015). ${ }^{4} \mathrm{NaCl}, \mathrm{CaCl}_{2} \cdot 2 \mathrm{H}_{2} \mathrm{O}, \mathrm{Na}_{2} \mathrm{HPO}_{4} \cdot 12 \mathrm{H}_{2} \mathrm{O}$, and $\mathrm{HCl}$ were dissolved in DI water so as to set the final $\mathrm{Na}^{+}$, $\mathrm{Ca}^{2+}, \mathrm{Cl}^{-}$and $\mathrm{HPO}_{4}{ }^{2-}$ concentrations to $141.0 \mathrm{mM}, 2.5 \mathrm{mM}$, $165.0 \mathrm{mM}$ and $1.0 \mathrm{mM}$, respectively. The CNCs aqueous suspension (1.044 g) was added to the prepared SBF $(200.0 \mathrm{~mL})$ in a flask with a calcium ion (in SBF solution) and sulfonic group (in CNCs) molar ratio of $13: 1$. The suspension was then stirred until no bulk CNCs particles were apparent and then transferred to an ultrasonic water bath for $30 \mathrm{~min}$ to evenly disperse CNCs. The mixture was then adjusted to different $\mathrm{pH}$ values with tris(hydroxymethyl)aminomethane solution (50 g $\left.\mathrm{L}^{-1}\right)$. Next, the suspension was put in an orbital shaker at $37{ }^{\circ} \mathrm{C}$ and $150 \mathrm{rpm}$ for $1 \mathrm{~h}$. This process of ultrasound and subsequent mild stirring was repeated three times. The solid contents in suspensions were then collected by centrifugation at $1705 \mathrm{~g}$ for $10 \mathrm{~min}$ and washed with anhydrous ethanol three times to remove the residual salts. Finally, the CNCs/HAP composites were dried for two days in a conventional oven at $45{ }^{\circ} \mathrm{C}$.

\subsection{Preparation of porous CNCs/HAP scaffolds}

The porous scaffolds were prepared by freeze-casting $5 \%(\mathrm{w} / \mathrm{w})$ CNCs or CNCs/HAP suspensions solidified by directional freezing (DF), plunging in liquid $\mathrm{N}_{2}\left(\mathrm{PL},-196^{\circ} \mathrm{C}\right)$ and putting in a $-20{ }^{\circ} \mathrm{C}$ freezer (FZ). This was accomplished by adding dry CNCs and CNCs/HAP sample in DI water under magnetic stirring for $2 \mathrm{~h}$ to obtain a homogeneous suspension with $5 \mathrm{wt} \%$ consistency. Then, $\sim 3.5 \mathrm{~mL}$ of the solutions were transferred into $10 \mathrm{~mL}$ glass vials and frozen by $\mathrm{FZ}\left(-20{ }^{\circ} \mathrm{C}\right.$ for $\left.24 \mathrm{~h}\right), \mathrm{PL}$ $\left(-196{ }^{\circ} \mathrm{C}\right.$ for $\left.10 \mathrm{~min}\right)$ or $\mathrm{DF}\left(-196^{\circ} \mathrm{C}\right.$ for $\left.10 \mathrm{~min}\right)$. In the case of $\mathrm{DF}$, only the bottom of the vials contacted liquid $\mathrm{N}_{2}$ and vertical heat transfer was prevented by insulation of the vials with polystyrene foam. Upon solidification, the samples were immediately put in a freeze drier $\left(-80{ }^{\circ} \mathrm{C}\right.$ and $\left.12 \mathrm{~Pa}\right)$ for $48 \mathrm{~h}$ to obtain the porous scaffolds.

\subsection{Characterization of nanocomposites}

The surface morphology of the CNCs/HAP composites and the longitudinal side view of the porous scaffolds were observed employing a SEM (Zeiss EVO MA15, Germany) at an accelerating voltage of $5 \mathrm{kV}$. Before SEM analysis, the samples were put in a $70{ }^{\circ} \mathrm{C}$ oven to remove the moisture and then sputter coated with gold. The dimensions of CNCs or CNCs/HAP fibers were observed by TEM. Before the TEM analysis, samples were placed in DI water to obtain a $0.02 \%(\mathrm{w} / \mathrm{v})$ solution. A drop of the diluted solution was then deposited on a carbon-coated copper grid to improve the dispersion of the CNCs. The residual water was removed with a filter paper from the periphery of the copper grid and dried in the air for $1 \mathrm{~min}$. The specimens were observed using a Zeiss TEM (Zeiss Libra 200 MC, Germany) with an acceleration voltage of $200 \mathrm{kV}$. The lengths and widths of the CNCs and CNCs/HAP composite were analyzed with ImageJ software, and around 100 fibers were selected for characterization. ${ }^{25}$ SAED patterns were obtained with the same TEM based on the selected areas in the TEM images. FTIR analysis was accomplished using a Nicolet 6700 spectrometer (Thermo Scientific, MA, USA). Spectral data was acquired in the transmittance mode with 16 scans at $4 \mathrm{~cm}^{-1}$ resolution over the range of 4000-500 $\mathrm{cm}^{-1}$. The XRD patterns were recorded using a D8 advanced instrument (Bruker, Germany) with $\mathrm{Cu} \mathrm{K} \alpha$ radiation at a voltage of $40 \mathrm{kV}$ and a current of $30 \mathrm{~mA}$. The scanning speed was $2^{\circ} \min ^{-1}$ within the $2 \theta$ angular range of $5-60^{\circ}$.

Thermogravimetric analysis (TGA) was carried out using a Q5000 instrument (TA Instruments, New Castle, DE, USA). About 5-10 mg of the nanocomposites were analyzed from RT to $700{ }^{\circ} \mathrm{C}$ at a heating rate of $10{ }^{\circ} \mathrm{C} \mathrm{min}^{-1}$ under high-purity 
nitrogen. The HAP content in the nanocomposites was also determined by TGA following a published methodology except for that technical air $\left(79 \% \mathrm{~N}_{2}\right.$ and $\left.21 \% \mathrm{O}_{2}\right)$ was used to facilitate complete combustion of organic compounds in the samples. ${ }^{26}$ The HAP contents were then calculated based on the initial and residual weights of the samples.

The porosity of different samples was determined according to a modified displacement method in a previous report. ${ }^{27}$ In brief, the volume and weight of the cylindrical foams were measured as $V_{0}$ and $W_{0}$, respectively. The volume was calculated based on the diameter and height of the cylinder determined by a digital Vernier caliper. Then the specimen was immersed into anhydrous ethanol for $48 \mathrm{~h}$ until saturation. The weight of the saturated foam was measured as $W_{1}$. Finally, the porosity of the samples was obtained as the formula of $P=\left(W_{1}-W_{0}\right) /\left(\rho \times V_{0}\right)$, where $\rho$ is the density of the anhydrous ethanol $\left(0.789 \mathrm{~g} \mathrm{~mL}^{-1}\right)$. Measurements were made on three samples of each foam, and the results represent an average value. Compression strength of different nanocomposite foams was determined with an INSTRON 5567 universal test machine (Canton, MA, USA) using a load cell of $500 \mathrm{~N}$. The cylindrical foams were subjected to a constant compression rate of $0.1 \mathrm{~mm} \mathrm{~s}^{-1}$ until $80 \%$ strain and the compression modulus was calculated from the initial linear region $(5 \%)$ of the stress-strain curve. Samples were stored in a desiccator before analysis.

\section{Results and discussion}

\subsection{Synthesis of CNCs/HAP nanocomposites}

Simulated body fluid (SBF) is a solution containing inorganic ions similar to those in human blood plasma which includes $\mathrm{Ca}^{2+}, \mathrm{Na}^{+}, \mathrm{PO}_{4}{ }^{3-}$ and $\mathrm{Cl}^{-}$as its main ions. SBF has been widely used to evaluate the bioactivity of different materials by forming the apatite layer on its surface. ${ }^{18}$ Unlike conventional bone substitutes such as titanium and stainless steel alloys, HAP crystals formed in SBF are nanosized and tend to grow and elongate in the $c$ axis (vertical orientation), the same as the orientation in real bones. ${ }^{25}$ The original SBF solution developed by Kokubo (1991) is composed of various inorganic ions such as $\mathrm{Na}^{+}, \mathrm{K}^{+}, \mathrm{Mg}^{2+}, \mathrm{Ca}^{2+}, \mathrm{Cl}^{-}, \mathrm{HCO}_{3}{ }^{-}, \mathrm{HPO}_{4}{ }^{2-}$ and $\mathrm{SO}_{4}{ }^{2-} \cdot{ }^{28}$ However, a recent study illustrated the presence of $\mathrm{Mg}^{2+}, \mathrm{HCO}_{3}{ }^{-}, \mathrm{SO}_{4}{ }^{2-}$ had only a slight effect on the formation and deposition of the HAP crystals. ${ }^{29}$ Thus, a simplified SBF containing $\mathrm{Ca}^{2+}, \mathrm{Na}^{+}, \mathrm{Cl}^{-}$, and $\mathrm{HPO}_{4}{ }^{2-}$ was adopted in this study and this is consistent with the literatures. ${ }^{4,30,31}$ The existence of a large amount of $\mathrm{Na}^{+}$ and $\mathrm{Cl}^{-}$is necessary to equalize the ion strength. The SBF is a metastable solution, and no HAP crystals were observed under the mild $\mathrm{pH}$ condition if no high-affinity substrate was introduced. ${ }^{29}$ In this study, CNCs were employed as a substrate to facilitate the deposition of HAP. To investigate the HAP coating, different $\mathrm{pH}$ values of 6.0 (acid condition), 7.4 (body condition) and 8.5 (basic condition) were chosen and the morphologies of CNCs after HAP coating were analyzed with SEM (as shown in Fig. 1). SEM images clearly indicated the successful synthesis of the CNCs/HAP composite. Specifically, the surface of CNCs was flat and neat (Fig. 1a), whereas after immersion in SBF at pH 6.0, a small amount of grain-like HAP particles could be seen
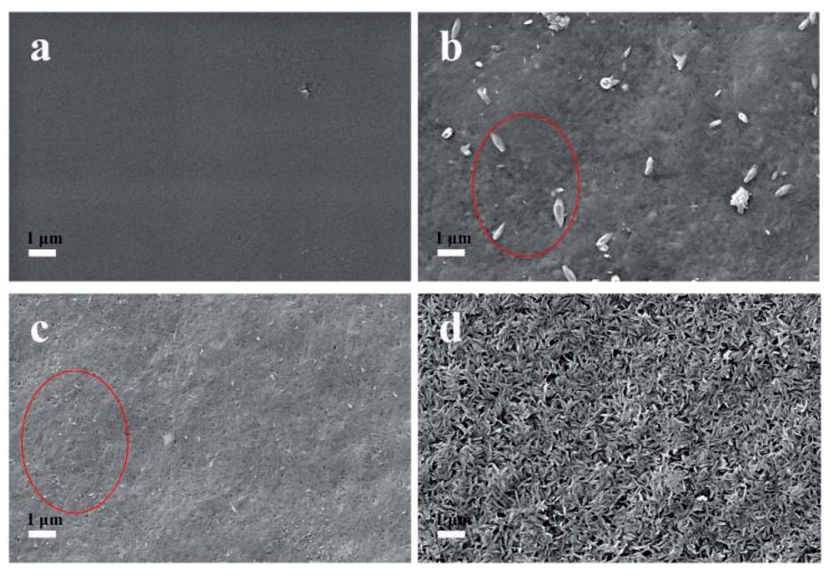

Fig. 1 The SEM images of CNCs before and after hydroxyapatite (HAP) coating. (a) Pure CNCs; (b) at SBF of pH 6.0; (c) at SBF pH 7.4; (d) at SBF pH 8.5.

embedded into the CNCs matrix (Fig. 1b). The deposition of HAP is primarily induced by the anionic functional groups (i.e., sulfonic and hydroxyl groups) on the surface of CNCs that can initiate the nucleation of HAP and promote the coating of HAP on CNCs matrix. ${ }^{4}$ Increasing the $\mathrm{pH}$ to 7.4 , the particles became smaller compared to the ones accomplished at $\mathrm{pH}$ 6.0. At a higher $\mathrm{pH}$ value of 8.5, small HAP particles aggregated due to the strong electrostatic interactions with CNCs and became predominant in the SEM image (Fig. 1d). It is known that HAP is soluble in an aqueous solution under acidic conditions. On the other hand, HAP tends to aggregate at high $\mathrm{pH}$ values. In our study, at the pH values of 6.0 and 7.4, only a few HAP deposits on CNCs were observed. Further increasing the $\mathrm{pH}$ to 8.5 significantly promoted the growth of the CNCs/HAP composites.

\subsection{Structure characterization}

3.2.1. FTIR and XRD analysis of the nanocomposites. During the HAP coating process, the CNCs and HAP were combined by hydrogen bonds between sulfonic and hydroxyl groups or by the formation of ionic bonds (including [HO] $-\mathrm{Ca}^{2+}$ and $\left[\mathrm{HSO}_{3}\right]-\mathrm{Ca}^{2+}$ ) through the hydroxyl and sulfonic groups and calcium ions in HAP and CNCs. ${ }^{22}$ To analyze the structure changes during the HAP coating process, FTIR was employed, and results are shown in Fig. 2a. The FTIR spectrum of CNCs exhibited an adsorption at $1637 \mathrm{~cm}^{-1}$, which is due to the $\mathrm{O}-\mathrm{H}$ bending of the water adsorbed by cellulose. ${ }^{32}$ Typical peaks of CNCs can be observed at $1428 \mathrm{~cm}^{-1}\left(\mathrm{CH}_{2}\right.$ scissoring motion), $1369 \mathrm{~cm}^{-1}$ (C-H bending), $1337 \mathrm{~cm}^{-1}$ (O-H in-plane bending), $1316 \mathrm{~cm}^{-1}$ ( $\mathrm{CH}_{2}$ wagging vibration), $1159 \mathrm{~cm}^{-1}$ (C$\mathrm{C}$ ring stretching) and $1054 \mathrm{~cm}^{-1}$ (C-O-C stretching vibration). ${ }^{4,22}$ The band at $895 \mathrm{~cm}^{-1}$ was assigned to the cellulosic $\beta$ glycosidic linkages. ${ }^{33}$ Furthermore, the FTIR spectral data of the samples after the HAP coating showed all the typical signals of CNCs, indicating the existence of CNCs in the nanocomposite. Moreover, signals associated with functional groups in HAP emerged in the CNCs/HAP nanocomposites. The signal at $1020 \mathrm{~cm}^{-1}$ was due to the asymmetric stretching of the $\mathrm{P}-\mathrm{O}$ 

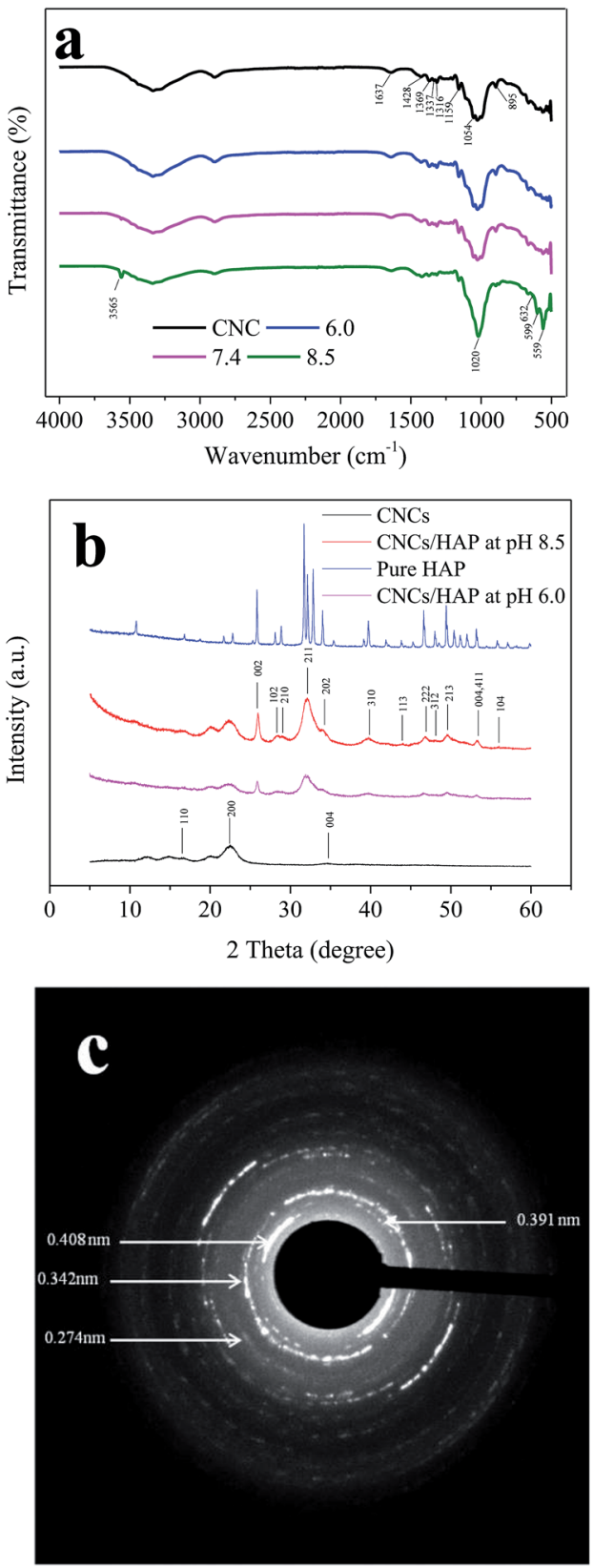

Fig. 2 FTIR (a), XRD (b) and SAED (c) analysis of the CNCs and HAP coated CNCs.

bonds in the phosphate group. ${ }^{34}$ The signals at $599 \mathrm{~cm}^{-1}$ and $559 \mathrm{~cm}^{-1}$ were assigned to be the degenerated bending of the O-P-O bonds. ${ }^{35}$ Also, signals at $3570 \mathrm{~cm}^{-1}$ and $632 \mathrm{~cm}^{-1}$ which represent the stretching and bending modes of hydroxyl groups in HAP could be also observed. ${ }^{36}$ These results revealed that the layer coated on CNCs is actual HAP rather than normal calcium phosphate. The HAP was further confirmed by measuring the $\mathrm{Ca} / \mathrm{P}$ ratio of the sample with an energy dispersive X-ray diffraction (EDX) attached to the SEM, which is a widely used technology to analyze the elements in HAP. ${ }^{18,34}$ EDX results showed that ratio of $\mathrm{Ca}$ and $\mathrm{P}$ in the nanocomposite was 1.76 which is consistent with the values in other reports and close to the value of 1.67 in natural human bone, indicating the coated layer was HAP. ${ }^{18,37,38}$ This higher $\mathrm{Ca} / \mathrm{P}$ ratio is likely to be caused by the generation of some other calcium contained salts like calcium carbonate and calcium hydroxide during the deposing process.

The crystalline structures of the pure CNCs, CNCs/HAP composites synthesized at $\mathrm{pH} 6.0$ and 8.5 , and pure HAP were analyzed by XRD (Fig. 2b). The characteristic peaks of cellulose at $16.7^{\circ}, 22.5^{\circ}$, and $34.7^{\circ}$ were assigned to the typical planes (110), (200) and (004) of cellulose, respectively. ${ }^{39}$ These diffraction peaks can also be found in numerous nanocellulose

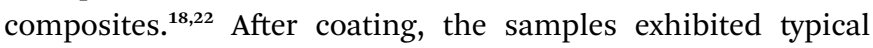
characteristic peaks of HAP at $2 \theta=26.0^{\circ}(002), 28.4^{\circ}(102), 29.0^{\circ}$

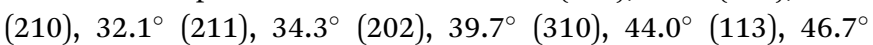
(222), $48.2^{\circ}(312), 49.7^{\circ}(213)$ and $56.1^{\circ}(104)$, respectively. The peaks at $53.4^{\circ}$ indicated planes $(004 / 411)$ presented in the HAP. ${ }^{40}$ All of these characteristic peaks of our synthesized HAP could be found in the pure HAP (Fig. 2b). In addition, it was found that the CNCs/HAP composites obtained at different $\mathrm{pH}$ values almost have the same crystalline structure, indicating that the $\mathrm{pH}$ has very limited effect on the structure of generated composites. The crystalline structure of the coating was further analyzed with SAED (Fig. 2c). The diffraction pattern exhibited several strong and broad diffuse rings, indicating the strong crystalline structure of the HAP. From the pattern, planes of (200), (002) and (111) could be clearly seen with $d_{200}=0.408 \mathrm{~nm}$, $d_{002}=0.342 \mathrm{~nm}$ and $d_{111}=0.391 \mathrm{~nm}$, respectively. In addition, an interplanar spacing of $0.274 \mathrm{~nm}$ could be found in the diffraction pattern which could be assigned to the planes of (211), (112) or (300) in the HAP. ${ }^{41,42}$ The crystalline results of XRD and SAED supported the FTIR result and confirmed the sample was composed of CNCs and HAP.

3.2.2. TEM images of the CNCs before and after HAP coating. To confirm the HAP is coated on the CNCs, we further adjusted the SBF $\mathrm{pH}$ to 8.5 without adding any CNCs substrates. However, no HAP precipitation was obtained in that condition, indicating the coating process was initiated by the negatively charged CNCs. The mechanism of the HAP deposition has been previously reported and involves HAP nucleation and subsequent growth. ${ }^{18}$ When the CNCs were added into the SBF, $\mathrm{Ca}^{2+}$ and $\mathrm{PO}_{4}{ }^{3-}$ could bind to the surface of the CNCs by ionic bonds and hydrogen bonds, and this process formed a stable nucleus. After that, the HAP nucleus grew and aggregated as more and more $\mathrm{Ca}^{2+}$ and $\mathrm{PO}_{4}{ }^{3-}$ attached to the CNCs and finally generated a HAP layer coated on the CNCs. This process is predisposed to occur under basic conditions. The images of the CNCs fibers before and after the HAP coating were measured by TEM and results are shown in Fig. 3. The dimensions of the original CNCs were determined to be $9.5 \mathrm{~nm}$ in width and $85.3 \mathrm{~nm}$ in length, which increased to $42.8 \mathrm{~nm}$ and $161.6 \mathrm{~nm}$, respectively, after coating most of the CNCs with fine HAP particles. This result indicated the coated HAP layer have a size around 16.7-38.2 nm (calculated by the increase of CNCs' width and length).

The synthesis process was optimized by adjusting the $\mathrm{pH}$ of the SBF from 5.0 to 11.0. Thermogravimetric analysis (TGA) method was used to analyze the content of HAP in different 

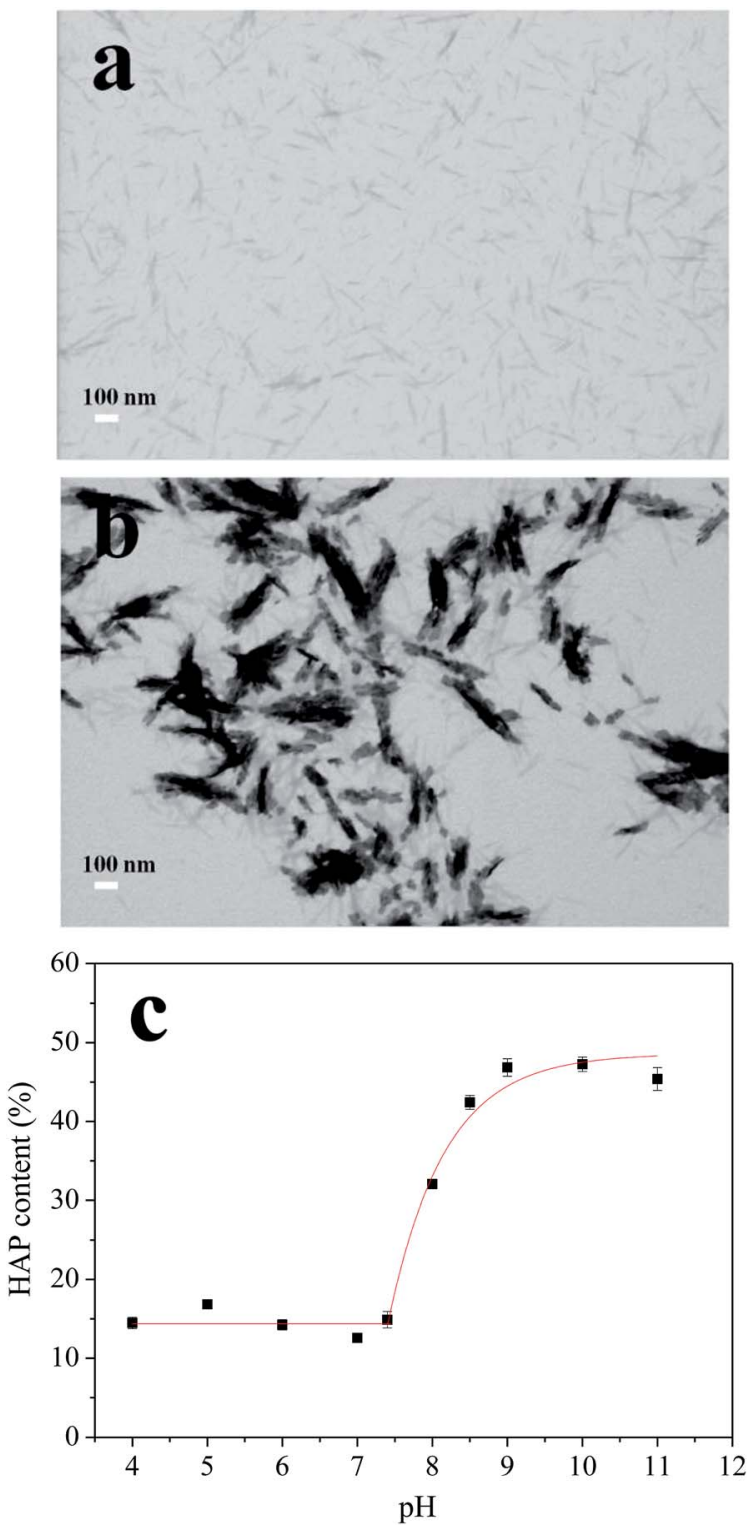

Fig. 3 Micrographs of CNCs before (a) and after (b) HAP coating, scale bars $100 \mathrm{~nm}$. The relationship between the HAP content and the $\mathrm{pH}$ values (c).

nanocomposites and results were shown in Fig. 3c. When the $\mathrm{pH}$ value of the SBF increased from 4.0 to 7.4 , the HAP contents in the nanocomposite were nearly constant $(\sim 15 \%)$. Further adjusting the SBF system to basic conditions, the HAP content increased exponentially by increasing $\mathrm{pH}$ values, with the highest content of $\sim 47 \%$ obtained at $\mathrm{pH} 9.0$. The deposition of HAP revealed a high degree of HAP supersaturation in the basic condition. Furthermore, when $\mathrm{pH}$ was increased beyond 9.0 to 10.0 and 11.0, HAP contents did not change that much which indicated that all of the $\mathrm{Ca}^{2+}$ and $\mathrm{PO}_{4}{ }^{3-}$ ions have deposited on CNCs at $\mathrm{pH}$ 9.0. These results suggested that the significant HAP coating process started at $\mathrm{pH} 7.4$ and saturated at $\mathrm{pH}$ 9.0. Therefore, $\mathrm{pH}$ values of 7.4 and 8.5, which were in this deposition $\mathrm{pH}$ range, were chosen for further experiments.

\subsection{Freeze-casting of the nanocomposite for porous scaffolds}

3.3.1. Morphology of freeze-casted foams by different freezing technologies. The porous structure of biomaterial plays an important role in tissue engineering in regards to promoting the desired cellular response and development of the new tissue. ${ }^{43}$ Pore size, shape, and volume of biomaterials can affect strength and ability of the regenerated tissues, and their uptake of nutrients and release of waste products. ${ }^{44}$ Freeze-casting has long been regarded as a versatile and promising technology to fabricate the porous scaffolds. ${ }^{45}$ This process involves freezing of water into ice crystals followed by sublimation of ice under reduced pressure. The resulting product is a porous structure material in which the pores are the replica of the ice. ${ }^{46}$ Thus, the freezing technology has a significant influence on the pore formation in the final foams.

In this study, nanocomposites prepared by HAP coating on CNCs were freeze-casted into porous foams by different freezing technologies including conventional freezing and directional freezing in liquid $\mathrm{N}_{2}$ (DF). The morphology of the freeze-casted foams is shown in Fig. 4. The samples prepared by directional freeze-casting had oriented and continuous channels (Fig. 4ac), compared to samples frozen by PL. During directional freezing, only the bottom of the vials was in contact with liquid $\mathrm{N}_{2}$, thus ice crystals were induced to grow vertically, parallel to the imposed temperature gradient. ${ }^{47}$ Moreover, it can be found that the size of channels in the pure CNC scaffold was around $534.3 \mu \mathrm{m}$, while it decreased to $217.0 \mu \mathrm{m}$ (at $\mathrm{pH} 7.4$ ) and 227.1 $\mu \mathrm{m}$ (at $\mathrm{pH} 8.5$ ) with the introduction of HAP. In addition, in the samples with only CNCs, pores in the channels were irregular and randomly distributed (Fig. 4a). With the addition of HAP, a more uniform and homogeneous pore structure was observed (Fig. 4b and c). This phenomenon was possibly caused by various adhesive forces (such as ionic bonds and hydrogen bonds) between CNCs and HAP that benefitted construction of a stable, uniform and oriented porous architecture. ${ }^{22}$ However, when the nanocomposites were solidified by plunging into the liquid $\mathrm{N}_{2}$, the ice crystals could nucleate at any places, and this resulted in a structure with randomly orientated pores (Fig. $4 \mathrm{~d}-\mathrm{f}$ ).

3.3.2. Thermal properties. The thermal stability and degradation properties of the scaffolds were measured by TGA under a $\mathrm{N}_{2}$ atmosphere and results are shown in Fig. 5. The curves of pure CNCs and low HAP content foams almost overlapped and included three weight loss regions. The first weight loss occurred near $105^{\circ} \mathrm{C}$, corresponding to the initial moisture loss. The main degradation appeared in the second region from $239{ }^{\circ} \mathrm{C}$ to $325{ }^{\circ} \mathrm{C}$, with weight loss of $64.9 \%$ and $62.0 \%$ for pure CNCs foam and foam prepared at $\mathrm{pH} 7.4$, respectively. This significant weight loss was primarily due to dehydration, depolymerization, and carbonization of the nanocomposites. ${ }^{\mathbf{4 8}}$ The last weight loss region between $325{ }^{\circ} \mathrm{C}$ and $450{ }^{\circ} \mathrm{C}$ is due to the further breakdown of the char into lower molecular weight gas compounds. Of significance, the thermal property of the nanocomposite was significantly improved with the incorporation of a large amount of HAP (sample prepared at $\mathrm{pH} 8.5$ ). The main degradation temperature region increased to $269-381{ }^{\circ} \mathrm{C}$ 

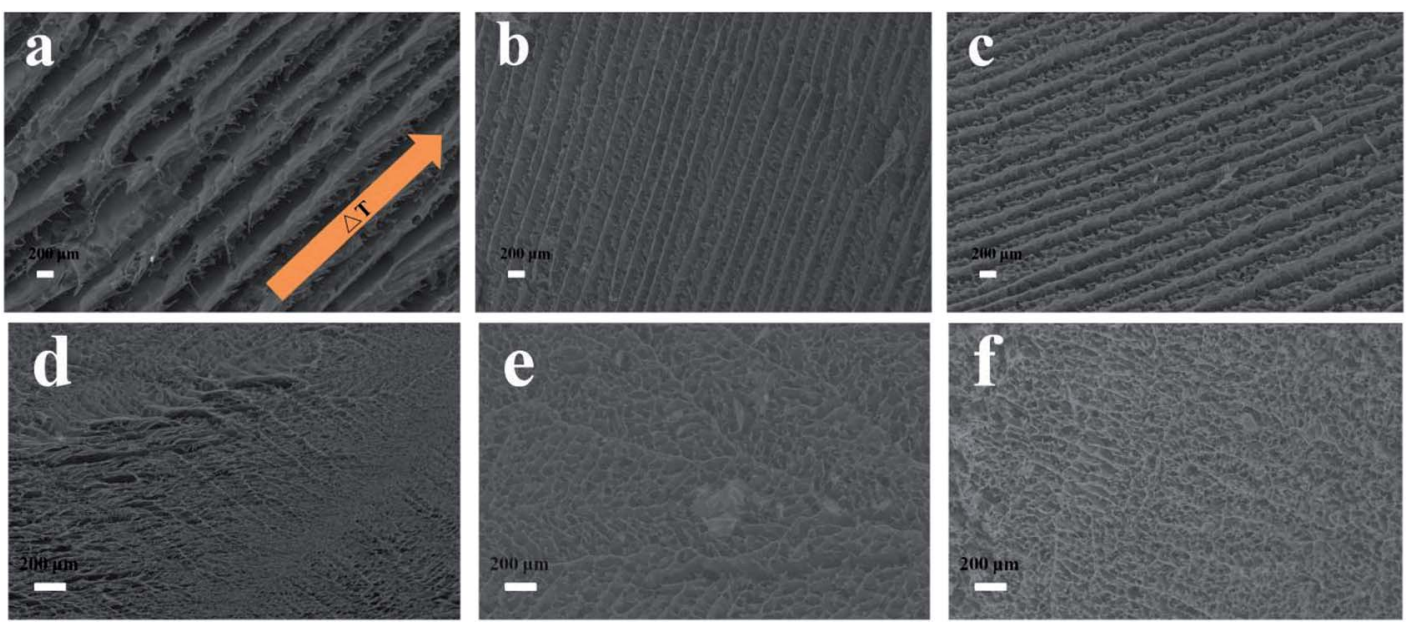

Fig. 4 SEM images of the longitudinal side views of the freeze-casted porous foams. $(a-c)$ Directionally frozen; ( $d-f)$ frozen by plunging into liquid $\mathrm{N}_{2}$. (a and d) Pure CNCs; (b and e) prepared at $\mathrm{pH} 7.4$; (c and f) prepared at $\mathrm{pH} 8.5$.

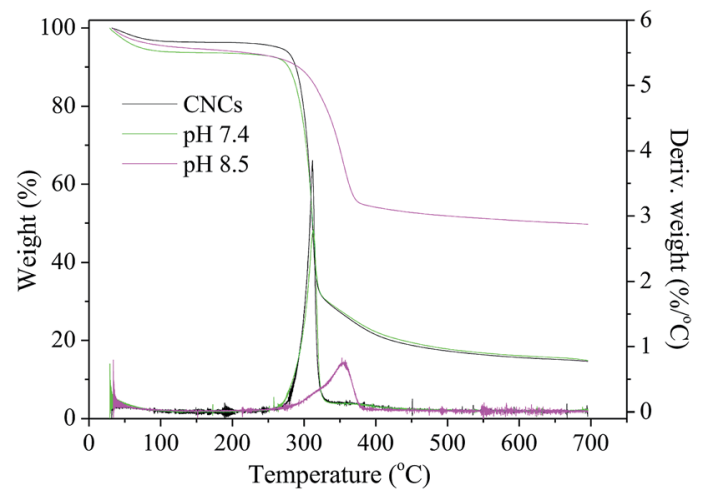

Fig. 5 TGA-DTG curves of the CNCs/HAP scaffolds.

with a weight loss of $54.9 \%$. In addition, it can be seen from the DTG curve that the maximum weight loss decreased from $3.9 \%$ (at $311{ }^{\circ} \mathrm{C}$ ) to $2.8 \%$ (at $313{ }^{\circ} \mathrm{C}$ ) and $0.8 \%$ (at $357^{\circ} \mathrm{C}$ ) per ${ }^{\circ} \mathrm{C}$, respectively, as the HAP content in the nanocomposites was increased, indicating the introduction of HAP is beneficial to the thermal property. This improvement was mainly attributed to the strong ionic and hydrogen bonds between CNCs and HAP and thus improved interfacial bonding in the mixture. ${ }^{2}$

3.3.3. Porosity, density and mechanical property of the scaffolds. The porosity of the samples was determined by the ethanol displacement method and the results are shown in Table 1. The results demonstrated that the porosity of the scaffold was significantly related to the solidifying methods employed (i.e. freezing temperature: $\mathrm{FZ}>\mathrm{DF}>\mathrm{PL}$ ). The samples acquired by FZ freezing showed a higher porosity than freezing by PL and DF. For example, the porosity of pure CNCs foam increased from $83.2 \%$ (DF) to $85.6 \%$ (PL) and further reached $91.2 \%$ with solidification by FZ. The same findings have also been reported by other researchers, indicating the freezing methodology significantly affected pore formation and the FZ method at a higher freezing temperature contributed to pore formation and resulted in higher porosity. ${ }^{49}$ In addition, porosity tended to decrease with increasing HAP content in the nanocomposite. The porosity of the pure CNCs foam and the $\mathrm{CNCs} / \mathrm{HAP}$ prepared at $\mathrm{pH} 7.4$ were almost the same irrespective of the solidification method. However, porosity dropped by $\sim 10 \%$ by further increasing the HAP content to $42.4 \%$ (prepared at $\mathrm{pH}$ 8.5). This could be attributed to the increasing HAP content which could have occupied more interstitial space in the frozen samples, resulting in lowered porosity after ice sublimation. ${ }^{9}$ High porosity structure is beneficial to tissue growth. Generally, scaffolds with a porosity higher than $70 \%$ could significantly facilitate nutrient delivery, cell adhesion, and attachment. ${ }^{27}$ The porosity of the scaffolds from this study is consistent with other HAP contained material, showing high porosities that have met the requirement for bone substitute scaffold materials.

As to density, it also varied with the solidification method (Table 1). DF caused the highest density for all the three samples. For example, for CNCs/HAP nanocomposite prepared at $\mathrm{pH} 7.4$, density increased from 46.1 to 48.1 and $50.8 \mathrm{mg} \mathrm{cm}^{-3}$ with freezing methods of FZ, PL, and DF, respectively. This finding is consistent with the porosity results, as increased porosity results in decreased density. According to $\mathrm{Xu}$ et al. (2014), density variation of samples was caused by the volume shrinkage during the freeze-casting process, which indicated that DF had a higher volume shrinkage compared to other two technologies, thus leading to a higher density. Concerning the effect of HAP content on density, a slight increase was observed with increasing HAP content which could be explained by the fact that the HAP particle is heavier than CNCs. ${ }^{47}$

Scaffolds for bone substitution also need to be mechanically strong to provide enough structural stability to support cell adhesion. A recent study reported that a 20 times improvement in mechanical strength was obtained with the HAP coated CNCs, compared to the normal CNCs/HAP mixture. ${ }^{50}$ The compression results of the synthesized CNCs/HAP scaffolds from different solidification technologies are summarized in Table 1. The mechanical properties of the scaffolds were also significantly related to the freezing technologies (freezing 
Table 1 Porosity, density and compression results of the CNC/HAP scaffolds

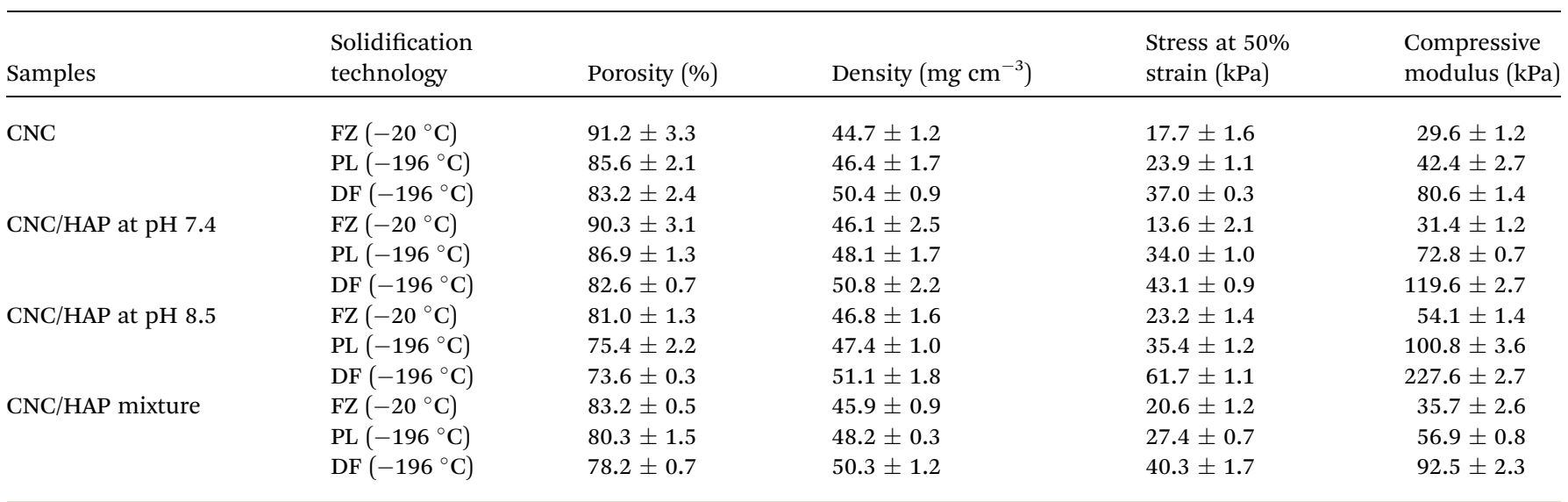

temperature: $\mathrm{FZ}>\mathrm{DF}>\mathrm{PL}$ ), including compressive stress and modulus, as shown in Table 1. For example, the compressive stress of CNCs scaffold increased from $17.7 \mathrm{kPa}$ to $23.9 \mathrm{kPa}$ and $37.0 \mathrm{kPa}$ when FZ was replaced by PL and DF. The same trend can also be found in compressive modulus which increased from $29.6 \mathrm{kPa}$ to $42.4 \mathrm{kPa}$ and $80.6 \mathrm{kPa}$ with different freezing methods. It could be concluded that both the freezing rate and freezing direction affected the mechanical properties. As observed, the fast freezing rate improved the mechanical properties (comparing PL to FZ). Moreover, the best compression results were obtained for the DF samples indicating that the oriented structure of the scaffold with strong anisotropy also improved the mechanical properties. During DF, ice crystals were induced to grow vertically, along with the direction of the imposed thermal gradient. The process formed an oriented and continuous channel architecture parallel to the direction of the compression force, this may explain why the DF resulted in the better mechanical performance than FZ and PL. On the other hand, with the coating of HAP, both the compression stress and compression modulus significantly increased, with highest values of $61.7 \mathrm{kPa}$ and $227.6 \mathrm{kPa}$ obtained with the nanocomposite at $\mathrm{pH}$ 8.5. This enhancement could be attributed to the improvement of stress transfer from the CNCs matrix to the strong HAP particles, and thus resulting in the superior mechanical properties. We further investigated the mechanical properties of the plain CNCs/HAP mixture (with the HAP content same to the CNCs/HAP composite prepared at $\mathrm{pH}$ 8.5), as shown in Table 1. The highest mechanical stress and modulus of the CNCs/HAP mixture were $40.3 \mathrm{kPa}$ and $92.5 \mathrm{kPa}$ (prepared by DF), respectively, which were much lower than our CNCs/HAP composite due to the heterogeneous dispersion of HAP in CNCs. This result indicated that our in situ HAP coated CNCs composite was superior to the CNCs/HAP mixture. Although the mechanical strength is still lower than a actual bone, we've made an improvement compared to some other bone scaffolds, including 8.13 times compression modulus of a chitosan-hyaluronic acid scaffold, ${ }^{51} 6$ times of a 3-D HAP composite, ${ }^{52}$ and 2.0 times of a hydrogel/fiber scaffold, ${ }^{53}$ which holds the potential for application as a substitute to the traditional metallic materials and bioceramics due to its biocompatibility. Further bone cell- related research will be done in the following experiment to test its perspective as a real bone substitute.

\section{Conclusion}

Our study illustrated a facile approach to fabricate a biomimetic scaffold by cultivating the CNCs in a simulated body fluid. With such methodology, the HAP was successfully coated on the CNCs, having a HAP layer size around 16.7-38.2 nm. The HAP content of the nanocomposite could be controlled by adjusting the $\mathrm{pH}$ of the solution, with the highest value of $\sim 47 \%$ prepared at $\mathrm{pH}$ 9.0. Moreover, after being freeze-casted into solid scaffolds, these nanocomposites all showed high porosity (higher than $70 \%$ ) and light weight (density around $50 \mathrm{mg} \mathrm{cm}^{-3}$ ). Compression results indicated the introduction of HAP increased the compressive properties of the freeze-casted scaffolds. On the other hand, the scaffolds solidified by DF have a better mechanical property than by PL and FZ due to the orientated structure it caused. These results demonstrated that the use of such in situ HAP coating followed by the directional freezing technology generated a biomimetic scaffold with high porosity and improved mechanical strength that can serve as a potential substitute for native bone.

\section{Conflicts of interest}

The authors declare no competing financial interests.

\section{Acknowledgements}

The authors thank the Priority Academic Program Development of Jiangsu Higher Education Institution (PAPD) and the Doctorate Fellowship Foundation of Nanjing Forestry University for supporting the work presented in this paper.

\section{References}

1 K. Shahzadi, I. Mohsin, L. Wu, X. Ge, Y. Jiang, H. Li and X. Mu, ACS Nano, 2017, 11, 325-334.

2 F. S. L. Bobbert and A. A. Zadpoor, J. Mater. Chem. B, 2017, 5, 6175-6192. 
3 S. Subramaniam, Y. H. Fang, S. Sivasubramanian, F. H. Lin and C. P. Lin, Biomaterials, 2016, 74, 99-108.

4 M. Ishikawa, Y. Oaki, Y. Tanaka, H. Kakisawa, G. SalazarAlvarez and H. Imai, J. Mater. Chem. B, 2015, 3, 5858-5863.

5 M. J. Olszta, X. Cheng, S. S. Jee, R. Kumar, Y. Y. Kim, M. J. Kaufman, E. P. Douglas and L. B. Gower, Mater. Sci. Eng., $R$, 2007, 58, 77-116.

6 M. Sadat-Shojai, M. T. Khorasani, E. Dinpanah-Khoshdargi and A. Jamshidi, Acta Biomater., 2013, 98, 7591-7621.

7 H. P. Schwarcz, D. Abueidda and I. Jasiuk, Front. Phys., 2017, $5,39$.

8 F. Heidari, M. Razavi, M. E. Bahrololoom, M. Yazdimamaghani, M. Tahriri, H. Kotturi and L. Tayebi, Ceram. Int., 2018, 44, 275-281.

9 D. Mao, Q. Li, N. Bai, H. Dong and D. Li, Carbohydr. Polym., 2018, 180, 104-111.

10 K. H. Zuo, Y. P. Zeng and D. Jiang, Mater. Sci. Eng., C, 2010, 30, 283-287.

11 S. Chopra, S. Mahdi, J. Kaur, Z. Iqbal, S. Talegaonkar and F. J. Ahmad, J. Pharm. Pharmacol., 2010, 58, 1021-1032.

12 K. Hashima, S. Nishitsuji and T. Inoue, Polymer, 2010, 51, 3934-3939.

13 D. Huang and A. Wang, RSC Adv., 2013, 3, 1210-1216.

14 M. Holzwarth and P. X. Ma, Biomaterials, 2011, 32, 96229629.

15 J. M. Dugan, J. E. Gough and S. J. Eichhorn, Biomacromolecules, 2010, 11, 2498-2504.

16 R. J. Moon, A. Martini, J. Nairn, J. Simonsen and J. Youngblood, Chem. Soc. Rev., 2011, 40, 3941-3994.

17 A. Dufresne, Mater. Today, 2013, 16, 220-227.

18 J. Si, Z. Cui, Q. Wang, Q. Liu and C. Liu, Carbohydr. Polym., 2016, 143, 270-278.

19 T. Abitbol, A. Rivkin, Y. Cao, Y. Nevo, E. Abraham, T. BenShalom, S. Lapidot and O. Shoseyov, Curr. Opin. Biotechnol., 2016, 39, 76-88.

20 B. Wicklein, A. Kocjan, G. Salazar-Alvarez, G. Carosio, G. Camino, M. Antonietti and L. Bergstrom, Nat. Nanotechnol., 2015, 10, 277-283.

21 H. Jiang, Y. Zuo, Q. Zou, H. Wang, J. Du, Y. Li and X. Yang, ACS Appl. Mater. Interfaces, 2013, 5, 12036-12044.

22 A. Kumar, Y. S. Negi, V. Choudhary and N. K. Bhardwaj, Cellulose, 2014, 21, 3409-3426.

23 C. S. Herdocia-Lluberes, S. Laboy-Lopez, S. Morales, T. J. Gonzalez-Robles, J. A. Gonzalez-Feliciano and E. Nicolau, J. Nanomater., 2015, 1-9.

24 S. Saska, H. S. Barud, A. M. M. Gaspar, R. Marchetto, S. J. L. Ribeiro and Y. Messaddeq, Int. J. Biomater., 2011, 2011, 175362.

25 F. Lindberg, J. Heinrichs, F. Ericson, P. Thomsen and H. Engqvist, Biomaterials, 2008, 29, 3317-3323.

26 D. Gebauer, V. Oliynyk, M. Salajkova, J. Sort, Q. Zhou, L. Bergström and G. Salazar-Alvarez, Nanoscale, 2011, 3, 3563-3566.
27 L. Y. Jiang, Y. Li, X. Wang, L. Zhang, J. Wen and M. Gong, Carbohydr. Polym., 2008, 74, 680-684.

28 T. Kokubo, Biomaterials, 1991, 12, 155-163.

29 T. Kobayashi, S. Ono, S. Hirakura, Y. Oaki and H. Imai, CrystEngComm, 2012, 14, 1143-1149.

30 Y. He, X. Wang, L. Chen and J. Ding, J. Mater. Chem. B, 2014, 2, 2220-2227.

31 J. Zhao, Z. Zhang, Z. Yu, Z. He, S. Yang and H. Jiang, Appl. Surf. Sci., 2014, 289, 89-96.

32 M. L. Troedec, D. Sedan, C. Peyratout, J. R. Bonnet, A. Smith, R. Guinebretiere, V. Gloaguen and P. Krausz, Composites, Part A, 2008, 39, 514-522.

33 C. Huang, A. J. Ragauskas, X. Wu, Y. Huang, X. Zhou, J. He, C. Huang, C. Lai, X. Li and Q. Yong, Bioresour. Technol., 2017, 250, 365-373.

34 J. Ryu, S. H. Ku, H. Lee and C. B. Park, Adv. Funct. Mater., 2010, 20, 2132-2139.

35 G. Wei, J. Reichert, J. Bossert and K. D. Jandt, Biomacromolecules, 2008, 9, 3258-3267.

36 X. Cai, H. Tong, X. Shen, W. Chen, J. Yan and J. Hu, Acta Biomater., 2009, 5, 2693-2703.

37 E. P. Erasmus, R. Sule, O. T. Johnson, J. Massera and I. Sigalas, Sci. Rep., 2018, 8, 3699.

38 R. Rabadan-Ros, P. Mazón, S. Serena, M. A. Sainz, L. Meseguer-Olmo and P. N. DeAza, J. Eur. Ceram. Soc., 2017, 37, 2943-2952.

39 W. Chen, H. Yu, Y. Liu, P. Chen, M. Zhang and Y. Hai, Carbohydr. Polym., 2011, 83, 1804-1811.

40 S. Koutsopoulos, J. Biomed. Mater. Res., 2002, 62, 600-612.

41 E. I. Suvorova, F. Christensson, H. E. L. Madsen and

A. A. Chernov, J. Cryst. Growth, 1998, 186, 262-274.

42 E. I. Suvorova and P. A. Buffat, J. Microsc., 1999, 196, 46-58.

43 K. K. Mallick, J. Am. Ceram. Soc., 2009, 92, S85-S94.

44 E. Ebaretonbofa and J. R. G. Evans, J. Porous Mater., 2002, 9, 257-263.

45 Y. Zhou, S. Fu, Y. Pu, S. Pan, M. V. Levit and A. J. Ragauskas, RSC Adv., 2013, 3, 19272-19277.

46 T. Köhnke, A. Lin, T. Elder, H. Theliander and A. J. Ragauskas, Green Chem., 2012, 14, 1864-1869.

47 Z. Xu, Q. Sun, F. Huang, Y. Pu, S. Pan and A. J. Ragauskas, RSC Adv., 2014, 4, 12148-12153.

48 Q. Sun, A. Mandalika, T. Elder, S. S. Nair, X. Meng, F. Huang and A. J. Ragauskas, Green Chem., 2014, 16, 3458-3462.

49 L. Hu, C. A. Wang, Y. Huang, C. Sun, S. Lu and Z. Hu, J. Eur. Ceram. Soc., 2010, 30, 3389-3396.

50 C. Huang, N. Hao, S. Bhagia, M. Li, X. Meng, Y. Pu, Q. Yong and A. J. Ragauskas, Materialia, 2018, 4, 237-246.

51 H. Tan, C. R. Chu, K. A. Payne and K. G. Marra, Biomaterials, 2009, 30, 2499-2506.

52 S. Yunoki, T. Ikoma, A. Tsuchiya, A. Tsuchiya, A. Monkawa, K. Ohta, S. Sotome, K. Shinomiya and J. Tanaka, J. Biomed. Mater. Res., Part B, 2007, 80, 166-173.

53 S. Khorshidi and A. Karkhaneh, J. Biomed. Mater. Res., 2017, 106, 718-724. 